1086

\section{CORELATIONS OF BODY MASS INDEX (BMI) \\ WITH LEPTIN LEVELS, CHOLESTEROL AND TRIGLYCERIDES IN OBESE CHILDREN}

\author{
O.I. Marginean \\ Pediatrics I, Medicine University Tg. Mures, \\ Târgu-Mures, Romania
}

In obese child, beside a BMl over 95 percentile, it is observed an increasing of triglycerides, cholesterol, LDL levels. Circulating leptin correlates with degree of obesity.

The aim of our study is to find correlations between $\mathrm{BMI}$ in obese children and leptin levels, cholesterol, triglycerides, glycemia, and to corroborate these dates with those of the mothers of obese children.

Matherial and method: The study included 121 children with BMI between 18,26 and $37,72 \mathrm{~kg} /$ $\mathrm{m}^{2}$ and 81 mothers of these children. Childrens age was between 1,6 and 18 years-old. It was a prospective study based on a clinic monitoring paper, BMI at child and mother, determination of glycemia, triglycerides, cholesterol, HDL, LDL and leptin.

Results: The age of children included in study was $14.43 \pm 3.774$ years. On our lot, childrens' BMI was between 18,26 and $37,72 \mathrm{~kg} / \mathrm{m}^{2}$. The leptin was measured only at 86 children; the lot of these children was divided in two sublots: one correlated with high BMI, between 37,72-27.40 (41 cases), the other with low BMI, 27,16-23,10 (45 cases). On lot with high $\mathrm{BMl}$ it was observed a medium leptin level of $66.76 \pm 30.06 \mathrm{ng} / \mathrm{ml}$ and $\mathrm{Cl} 95 \%$ (57.27-76.25) with aplatization of Gauss curve, and on lot with low BMI the medium leptin was $53,00 \pm 26,19$ with $\mathrm{Cl} 95 \%$ : $45,13-60,87$. The leptin level correlates directly proportional with cholesterol and triglycerides.

Conclusion: On our lot it was observed an increasing of leptin levels at two lots and a correlation concerning cholesterol and triglycerides with $\mathrm{BMI}$ at children and mothers.

\section{SIGNIFICANCE OF SERUM CORTISOL IN PRETERM INFANTS WITH REFRACTORY HYPOTENSION}

\author{
S. Mitra, M. Karam, A. Arasu \\ Neonatal Unit, Luton and Dunstable Hospital NHS \\ Foundation Trust, Luton, UK
}

Background: A significant proportion of sick preterm infants suffer from systemic hypotension that is resistant to volume expansion and inotrope treatment. These infants respond readily to corticosteroids indicating a state of adrenocortical insufficiency.

Aim: Our aim was to look at serum cortisol level in sick preterm infants and any correlation between this level and the need for hydrocortisone therapy for refractory hypotension.

Method: A retrospective study looking at serum cortisol levels, taken before starting hydrocortisone therapy in ill preterm infants with refractory hypotension over one year period. Reference range for serum cortisol level in well preterm infants: 73$562 \mathrm{nmol} / \mathrm{l}$. Hydrocortisone dose schedule was 2.5 $\mathrm{mg} / \mathrm{kg} /$ dose given 6 hourly. Hydrocortisone was stopped at the earliest opportunity.

Result: Out of total 21 episodes, 4 episodes were excluded as they were repeat episodes in two infants. 17 preterm infants were included in the study (birth weight range $530 \mathrm{gms}-1224 \mathrm{gms}$ and corrected gestation range 25wks - 31wks 6 days). Range of serum cortisol level was between 153$415 \mathrm{nmol} / \mathrm{l}$. Hydrocortisone needed for these infants varied from 1 dose to 32 doses. There was no positive correlation noted between the cortisol level and need for hydrocortisone therapy. No relationship was noted between corrected gestational age and serum cortisol level.

Conclusion: Although sick preterm neonates had serum cortisol levels which were 'normal' for well preterm infants, this probably reflects a failure to respond to stress and relative inadequacy of cortisol production. Serum cortisol levels did not reflect the degree of need for hydrocortisone therapy in sick preterm infants. 